\title{
FORMULA SABUN SUSU SAPI DENGAN PENAMBAHAN EKSTRAK DAUN CENGKEH
}

\author{
Siti Fatimah ${ }^{1 *}$, Ulfa Nurul Marfu'ah ${ }^{2}$, Agung Abadi Kiswandono ${ }^{3}$ \\ ${ }^{1}$ Jurusan Teknik Kimia, Fakultas Teknik, Universitas Muhammadiyah Surakarta \\ ${ }^{2}$ Studi Teknik Kimia, Fakultas Teknik, Universitas Muhammadiyah Surakarta \\ Jl. A. Yani Mendungan Kartasura, Sukoharjo, Surakarta 57102. \\ ${ }^{3}$ Jurusan Kimia FMIPA Universitas Lampung, Bandar Lampung 35141
}

sf120@ums.ac.id

\begin{tabular}{|c|}
\hline Artikel Info \\
\hline $\begin{array}{l}\text { Diterima } \\
\text { tanggal } \\
11.12 .2020\end{array}$ \\
\hline $\begin{array}{l}\text { Disetujui } \\
\text { publikasi } \\
\text { tanggal } \\
\text { 30.04.2021 }\end{array}$ \\
\hline $\begin{array}{l}\text { Kata kunci : } \\
\text { Daun Cengkeh, } \\
\text { Ekstrak, NaOH, } \\
\text { Sabun Padat. }\end{array}$ \\
\hline
\end{tabular}

\begin{abstract}
ABSTRAK
Bagian terluar dari tubuh yang terkena paparan sinar ultraviolet adalah kulit. Terjadi penumpukan kotoran akibat dari pengaruh eksternal lingkungan, sehingga perlu adanya perlindungan dasar untuk merawat kulit dengan menggunakan sabun untuk menjaga kebersihan kulit. Sabun adalah bahan pembersih yang dibuat berdasarkan reaksi saponifikasi antara basa kalium atau natrium dan asam lemak (minyak). Penambahan bahan pengisi berupa daun cengkeh ditambahkan pada pembuatan sabun susu sapi sebagai bahan antiseptik dan aromatik. Kandungan bahan kimia yang terdapat pada cengkeh berupa flavonoid, minyak atsiri (eugenol) dan antibakteri. Metode pembuatan sabun dengan menggunakan cold process. Ekstraksi daun cengkeh dengan menggunakan ekstraksi suhu ruang dinggap proses yang paling sederhana dan variabel perbedaan komposisi $\mathrm{NaOH}$ yaitu $26 \%, 28 \%$, $30 \%$, 32\%, dan 34\%, lalu mengambil $150 \mathrm{~mL}$ dari masing -masing konsentrasi untuk melihat hasil sabun yang sesuai standar SNI. Pengujian sabun dilakukan dengan menggunakan standar SNI sabun padat dan uji organoleptik. Berdasarkan hasil pengujian sabun yang paling mendekati standar SNI yaitu $\mathrm{NaOH} 30 \%$.
\end{abstract}

\section{ABSTRACT}

The outer part of the body that is exposed to ultraviolet rays is the skin. There is an accumulation of dirt as a result of external environmental influences, so it is necessary to have basic protection to care for the skin by using soap to keep the skin clean. Soap is a cleaning agent made based on the saponification reaction between potassium or sodium bases and fatty acids (oil). The addition of fillers in the form of clove leaves is added to the manufacture of cow's milk soap as an antiseptic and aromatic ingredient. The chemical content found in cloves is in the form of flavonoids, essential oil (eugenol), and antibacterial. The method of making soap using a cold process. Extraction of clove leaves using room temperature extraction with the simplest process and variable differences in the composition of $\mathrm{NaOH}$, namely $26 \%, 28 \%, 30 \%, 32 \%$, and $34 \%$, then take $150 \mathrm{~mL}$ of each concentration to see the appropriate soap results. SNI standards. Soap testing was carried out using the SNI standard for solid soap and organoleptic tests. Based on the test results, the soap that is closest to the SNI standard is $30 \%$ of $\mathrm{NaOH}$.

http://dx.doi.org/10.23960/aec.v6.i1.2021.p56-65

Anal.Environ.Chem. 


\section{PENDAHULUAN}

Kulit bagian terluar tubuh berfungsi untuk melindungi tubuh bagian dalam tubuh lainnya dari gangguan eksternal lingkungan. Tempat keluarnya keringat atau sisa metabolisme dalam tubuh, fungsi pengindraan, ataupun sebagai pengaturan suhu tubuh. Paparan sinar ultraviolet dan kuman sering kali menjadi salah satu hal yang menjadi gangguan pada kulit, jika dibiarkan tanpa perawatan. Gangguan kulit berupa kulit kusam, jerawat ataupun penyakit kulit lainnya. Maka diperlukan agen pembersih kulit yang paling mendasar sebagai perlindunga utama yaitu sabun mandi.

Sabun adalah bahan pembersih yang dibuat berdasarkan reaksi saponifikasi antara basa kalium atau natrium dan asam lemak (minyak) (SNI, 2016). Bahan-bahan pembuatan sabun yang digunakan terdiri dari bahan utama dan bahan pendukung antara lain pewarnaan dan fragrance (pewangi). Bahan tersebut digunakan untuk meningkatkan nilai dan kualitas produk sabun. Jenis sabun yang sering dikenal, yaitu sabun padat (batangan) dan sabun cair (Hambali dkk., 2005 dan Kiswandono dkk., 2020). Metode pembuatan sabun berdasarkan suhu yang digunakan terdiri dari metode proses dingin (cold process) dan proses panas (hot process) (Asnani dkk., 2020; Mabrouk dkk., 2005). Perbedaan kedua proses tersebut terletak pada ada atau tidaknya proses pemanasan setelah reaksi penyabunana terjadi. Pemanasan bertujuan untun mempercepat penghilangan sisa alkali sehingga mempersingkat waktu curing. Sabun yang dihasilkan dari metode proses dingin memerlukan waktu curing 2-4 minggu. Untuk metode panas memerlukan waktu satu jam.

Pada penelitian kali ini menggunakan bahan baku susu sapi murni dan minyak sawit. Susu sapi yang bagus diperas langsung. Namun susu sapi hanya memiliki daya simpan yang cenderung singkat dan cenderung mudah rusak (perishable food). Kandungan susu sapi yang bagus untuk kulit yaitu vitamin D yang berguna untuk meringankan peradangan karena jerawat dan merangsang pembentukan sel kulit baru. Susu juga memberikan efek melembutkan dan mencerahkan kulit. Oleh karena itu, susu sapi banyak digunakan untuk produk-produk kecantikan seperti sabun mandi, sabun wajah, lotion dan lain sebagainya (Ramdan, 2019). Sedangkan bahan pendukung untuk aroma dan antiseptik pada sabun menggunakan ekstrak daun cengkeh. Pemilihan daun cengkeh dikarenakan jumlahnya yang sangat banyak di Pegunungan saat musim panen serta kurang dimanfaatkan oleh para petani.

http://dx.doi.org/10.23960/aec.v6.i1.2021.p56-65 
Daun cengkeh mengandung minyak atsiri atau disebut juga senyawa eugenol dengan karakteristik cairan berwarna bening atau kuning agak pucat, memiliki aroma yang menyegarkan dan pedas seperti bunga cengkeh kering. Minyak atsiri cengkeh sekitar 12-21\% dimana komponen utama dari senyawa tersebut adalah 95\% eugenol (Haryani dkk., 2017; Kardinan dkk., 1998). Tanaman yang mengandung flavonoid memiliki aktivitas antioksidan, antibakteri, antiradang antialergi, dan antikanker. Penambahan senyawa atau bahan antibakteri dapat meningkatkan kemampuan dari sabun sehingga sabun tersebut mengandung bahan antiseptik.

Pemilihan jenis asam lemak menentukan karakteristik sabun yang dihasilkan, karena setiap jenis asam lemak akan memberikan sifat yang berbeda pada sabun (Widyasanti, 2017). Asam lemak merupakan komponen utama penyusun lemak dan minyak, sehingga pemilihan jenis minyak yang akan digunakan sebagai bahan baku pembuatan sabun merupakan hal yang sangat penting. Untuk menghasilkan sabun dengan kualitas yang baik, maka harus menggunakan bahan baku dengan kualitas yang baik pula. Minyak kelapa ditambahkan untuk mendapatkan tekstur sabun saying lembut dan tekstur padat didapatkan dari penambahan minyak sawit.

\section{METODE}

\section{Alat dan Bahan}

Alat yang digunakan adalah timbangan, blender, cetakan sabun, baskom, saringan, plastik wrap, dan spatula. Bahan yang digunakan adalah minyak sawit, minyak kelapa, susu sapi murni, ekstrak daun cengkeh, dan Natrium hidroksida.

\section{Prosedur}

\section{Ekstraksi daun cengkeh}

Metode ekstraksi paling sederhana, ekstraksi dilakukan dengan menggunakan blender. 100 gram daun cengkeh kering dipotong kecil-kecil, ditambahkan dengan air sebanyak $500 \mathrm{~mL}$ air lalu dihaluskan dengan blender. Saring filtrat daun cengkeh. Proses ekstraksi daun cengkeh dapat dilihat pada Gambar 1. 


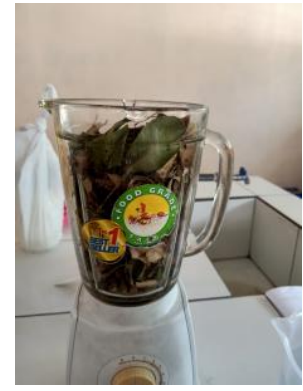

(a)

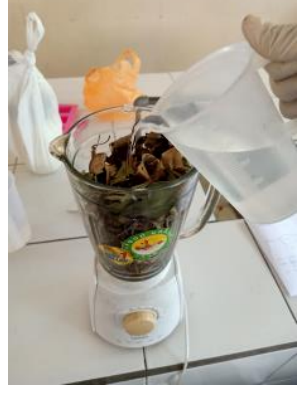

(b)

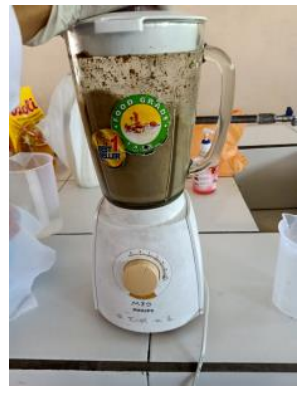

(c)

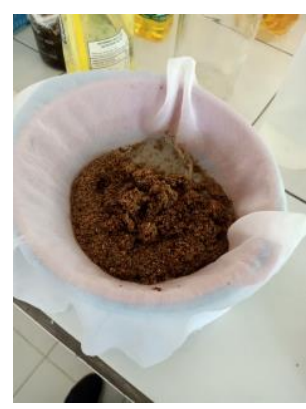

(d)

Gambar 1. Proses Ekstraksi Daun Cengkeh

(a) Memasukkan 100 gram daun cengkeh, (b) Menambah $500 \mathrm{~mL}$ air (c)Menghaluskan campuran, (d) Menyaring filtrat

\section{Penetapan Variabel}

Variabel tetap yaitu $150 \mathrm{~mL}$ ekstrak daun cengkeh, $280 \mathrm{~mL}$ minyak sawit dan $140 \mathrm{~mL}$ minyak kelapa. Variabel terikat yaitu konsentrasi $\mathrm{NaOH} 26 \%, 28 \%$, 30\%, 32\%, dan 34\% diambil masing-masing sebanyak $150 \mathrm{~mL}$. Takaran pembuatan masing-masing konsentrasi $\mathrm{NaOH}$ adalah seperti terlihat pada Tabel 1.

Tabel 1. Komposisi pembuatan larutan Natrium Hidroksida (NaOH)

\begin{tabular}{lccccc}
\hline Jumlah & $\mathbf{2 6 \%}$ & $\mathbf{2 8 \%}$ & $\mathbf{3 0 \%}$ & $\mathbf{3 2 \%}$ & $\mathbf{3 4 \%}$ \\
\hline Akuades (mL) & 250 & 250 & 250 & 250 & 250 \\
$\mathrm{NaOH}$ (gram) & 65 & 70 & 75 & 80 & 85 \\
& & & & & \\
\hline
\end{tabular}

\section{Pembuatan sabun}

Komposisi pembuatan sabun padat seperti terlihat pada Tabel 2. Campurkan $280 \mathrm{~mL}$ minyak sawit dan $140 \mathrm{~mL}$ minyak kelapa kedalam baskom, kocok hingga mengeluarkan busa (homogen). Tambahkan $215 \mathrm{~mL}$ larutan $\mathrm{NaOH}$ dan aduk hingga tercampur rata selama 5 menit. Tambahkan $150 \mathrm{~mL}$ ekstrak daun cengkeh dan aduk hingga tercampur rata. Masukkan adonan kedalam cetakan silikon. Tunggu hingga sabun menjadi padat sempurna. Sabun dapat digunakan 2 minggu setelahnya. Pembuatan sabun padat terlihat pada Gambar 2. 
Tabel 2. Komposisi Pembuatan Susu Padat

\begin{tabular}{lccccc}
\hline Bahan & S1 & S2 & S3 & S4 & S5 \\
\hline Minyak Sawit & 280 & 280 & 280 & 280 & 280 \\
Minyak Kelapa (mL) & 140 & 140 & 140 & 140 & 140 \\
NaOH $(26,28,30,32,34) \%(m L)$ & 215 & 215 & 215 & 215 & 215 \\
Ekstrak daun cengkeh $(\mathrm{mL})$ & 150 & 150 & 150 & 150 & 150 \\
\hline
\end{tabular}

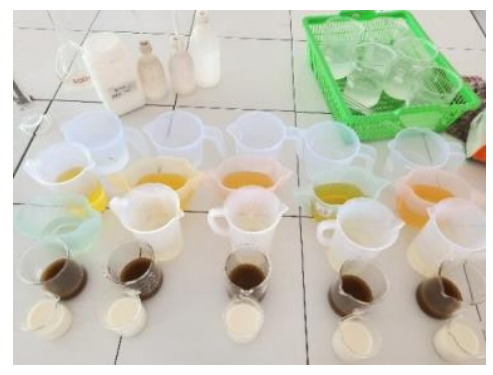

(a)

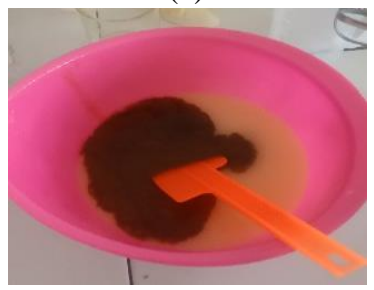

(d)

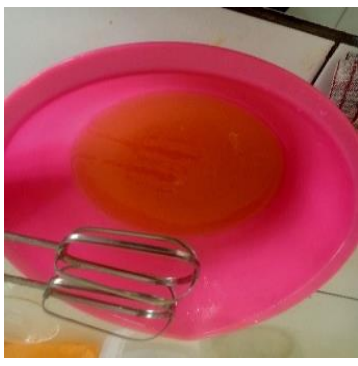

(b)

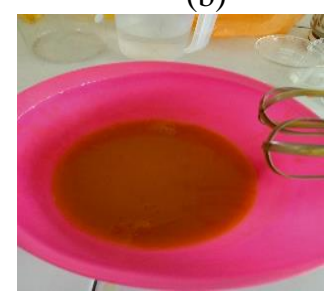

(e )

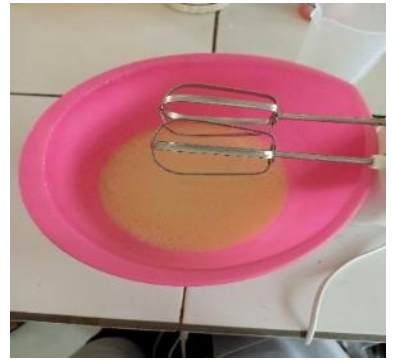

( c )

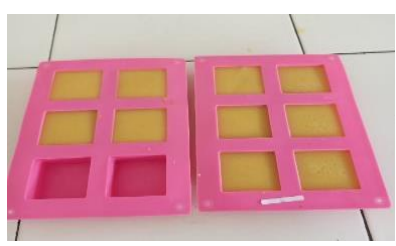

(f)

Gambar 2. Proses pembuatan Sabun Padat

(a) Menyiapkan bahan,(b) Mencampur $280 \mathrm{~mL}$ minyak sawit dan $140 \mathrm{~mL}$ minyak kelapa aduk hingga muncul busa, (c) Menambahkan $\mathrm{NaOH}$ sesuai variasi sebanyak $215 \mathrm{~mL}$, (d) Menambahkan $\mathrm{NaOH}$ sesuai variasi sebanyak $215 \mathrm{~mL}$, (e) Menuangkan adonan kedalam cetakan silikon, (f) Diamkan adonan selama 2 minggu

\section{Pengujian Sabun}

Pengujian kualitas sabun susu padat berdasarkan standar SNI 06-3532-1994 dan uji organoleptik bertujuan untuk mengetahui kelayakan dan kualitas dari sabun yang diproduksi. Pengujian meliputi uji kadar air, uji pH, uji stabilitas busa, uji alkali bebas, dan uji bilangan penyabunan. 


\section{HASIL DAN PEMBAHASAN}

\section{Analisa Kadar Air}

Uji kadar air dilakukan dengan mengoven 5 gram sabun dengan suhu $105{ }^{\circ} \mathrm{C}$ selama satu jam sampai berat sabun konstan. Pengujian dilakukan untuk menjaga kualitas sabun kadar air yang terlalu tinggi dapat menyebabkan sabun menjadi lembek dan berbau saat pengemasan. Berdasarkan Gambar 2. Sabun dengan $\mathrm{NaOH} 26 \%$, 28\%, 30\%, 32\% dan 34\% berturut-turut 2,3\%, 2,4\%, 2,5\%, 3,1\% dan 3,3\% sudah memenuhi standar SNI dibawah 15\%. Kadar air dengan perbedaan konsentrasi $\mathrm{NaOH}$ meningkat seiring dengan besarnya konsentrasi $\mathrm{NaOH}$ (Sa'diyah, 2018).

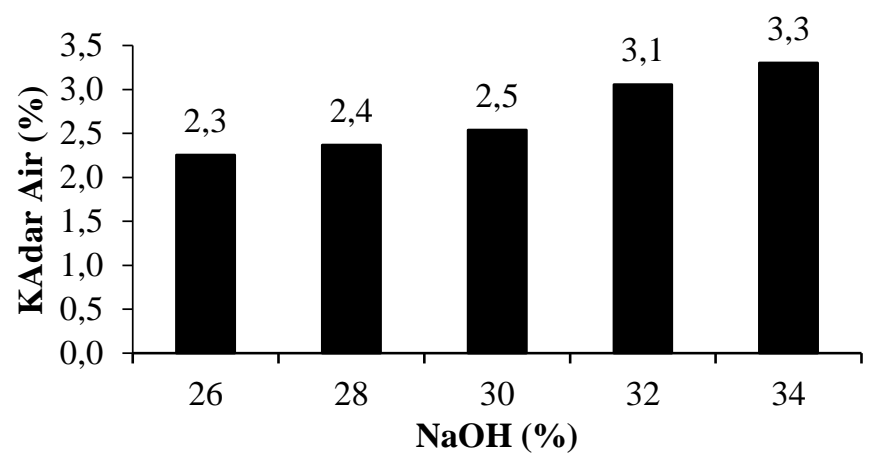

Gambar 3. Grafik Analisa Kadar Air

\section{Analisa Derajat Keasaman (pH)}

Pengujian derajat keasaman dilakukan dengan Menimbang satu gram sampel sabun susu padat. Melarutkan sampel sabun susu padat ke dalam $10 \mathrm{~mL}$ akuades, kemudian mencuci $\mathrm{pH}$ meter dengan akuades sebagai fungus kalibrasi. Memasukkan $\mathrm{pH}$ meter ke dalam larutan sabun dan mencatat $\mathrm{pH}$ yang terbaca. Pengujian ini bertujuan untuk mengetahui kelayakan dari sabun itu sendiri. Sabun yang terlalu basa dapat menimbulkan iritasi kulit, perih, dan terasa gatal saat digunakan, karena nilai $\mathrm{pH}$ mempengaruhi daya absorpsi di kulit. Umumnya $\mathrm{pH}$ sabun padat berkisar 8-10 (SNI, 2016). Selain itu, pH yang terlalu rendah atau tinggi dapat menyebabkan efek samping kulit menjadi kering (Sa'diyah, 2018). Pada Tabel 3 Analaisa Derajat Keasaman. Hasil uji pH, menunjukkan semakin besar kadar $\mathrm{NaOH}$ maka $\mathrm{pH}$ dari sabun akan semakin basa. Kadar maksimal sabun menurut SNI yaitu 11. Berdasarkan data yang diperoleh sabun dengan 
$\mathrm{NaOH} 30 \%$ memenuhi standar SNI sabun padat. $\mathrm{NaOH} 26 \%$ masih dibawah standar yang berarti masih besifat asam dan $\mathrm{NaOH} 32 \%, 36 \%$ diatas standar ynag berarti sabun terlalu basa.

Tabel 3. Analisa Derajat Keasaman $(\mathrm{pH})$

\begin{tabular}{cc}
\hline Kadar NaOH (\%) & pH \\
\hline 26 & 9 \\
28 & 10 \\
30 & 11 \\
32 & 12 \\
34 & 12 \\
\hline
\end{tabular}

\section{Analisa Alkali Bebas}

Alkali bebas merupakan alkali yang tidak habis bereaksi dengan asam lemak pada proses pembuatan sabun. Kadar alkali bebas menurut SNI (2016) yaitu 0,1\%. Penambahan konsentrasi alkali semakin besar menyebabkan alkali bebas yang dihasilkan melebihi standar. Alkali pada sabun tidak boleh melebihi standar SNI. Alkali yang terlalu tinggi dapat menyebabkan iritasi kulit, gatal dan perih, karena mempengaruhi daya absorpsi di kulit (Sa'diyah, 2018). Kulitas sabun yang dihasilkan semakin tinggi alkali sabun maka sabun akan mudah menyusut. Pada Gambar 4 terlihat grafik analisa kadar alkali. Sabun yang memenuhi standar SNI dari ke-5 sampel yaitu sabun $26 \%, 28 \%$ dan $30 \%$ dengan jumlah sebesar $0,01 \%, 0,03 \%$, dan $0,08 \%$.

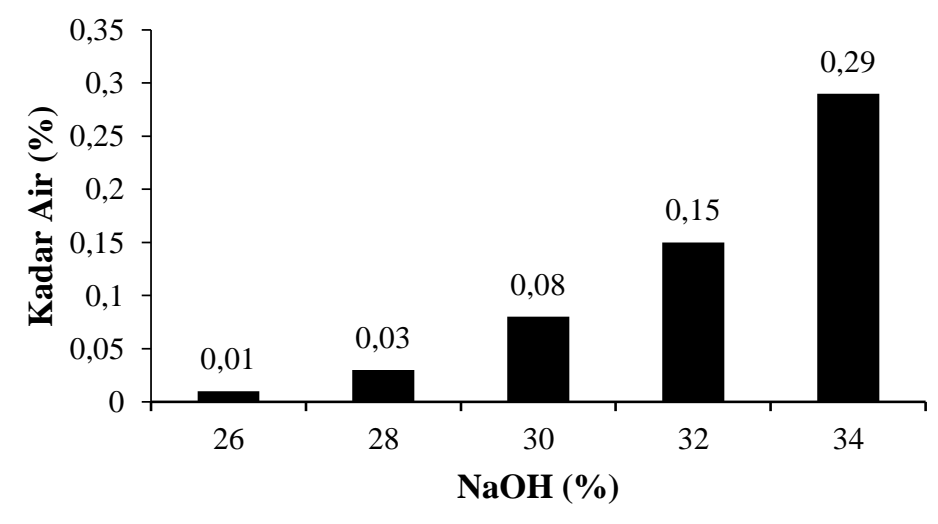

Gambar 4. Grafik Analisa kadar Alkali 


\section{Analisa Organoleptik}

Analisa organoleptik lebih memperhatikan penampakan (visual) dari sabun yang dihasilkan. Pengujian terdiri dari kekerasan sabun, warna, dan aroma.

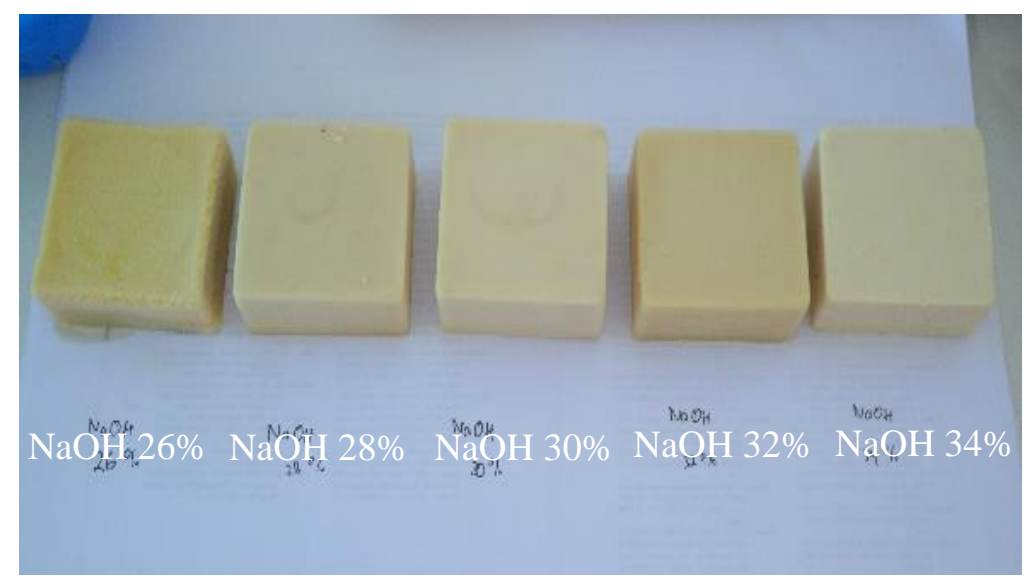

Gambar 5. Analisa Organoleptik Sabun

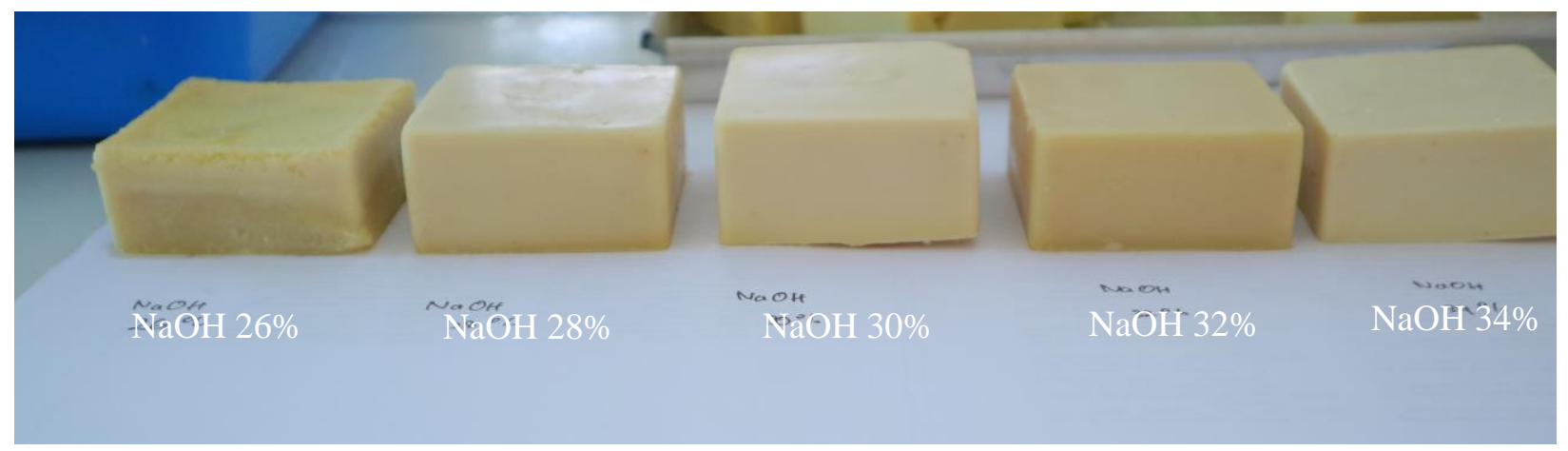

Gambar 6. Penampakan kekerasan sabun

Gambar 6 merupakan tekstur kekerasan sabun dengan variabel $\mathrm{NaOH} 26 \%$. Sabun ini memiliki tekstur lembek dibandingkan dengan sabun lainnya. Hal ini terjadi karena reaksi saponifikasi tidak terjadi secara merata dikarenakan alkali yang digunakan terlalu sedikit untuk membentuk sabun. Secara keseluruhan warna sabun sama berwarna kuning pudar yang berasal dari warna asli dari daun cengkeh kering, perlu ditambahkan pewarna sabun agar wrna sabun lebih menarik untuk dipasarkan ke konsumen. Karena mayoritas masyarakat indonesia menyukai sabun dari visualnya yang menarik untuk dibeli. Aroma dari sabun tidak tajam seperti khas daun cengkeh perlu dilakukan pengujian variasi metode ekstraksi untuk daun cengkeh agar aroma eugenolnya dapat berbau tajam. 


\section{KESIMPULAN}

Variabel $\mathrm{NaOH} 26 \%, 28 \%, 30 \%, 32 \%$, dan 34\% mempengaruhi kualitas dari sabun yang dihasilkan. Semakin besar konsentrasi $\mathrm{NaOH}$ maka semakin besar $\mathrm{pH}$, dan alkali bebas sabun. Formulasi sabun dengan variasi perbedaan $\mathrm{NaOH} 30 \%$ cenderung mendekati standar SNI dengan kadar air 2,5391\%, pH 11, dan alkali bebas 0,08\%. Uji organoleptik sabun secara keseluruhan untuk aroma sabun kurang terasa seperti bau daun cengkeh. Warna dari sabun kuning pusat seperti warna daun cengkeh, warna tergolong kurang menarik untuk dipasarkan. Kekerasan sabun menurut kadar $\mathrm{NaOH}$ yang ditambahkan semakin banyak maka kekerasan sabun semakin padat. Namun yang paling mendekati tekstur sabun pada umunya yaitu sabun dengan konsentrasi $\mathrm{NaOH} 30 \%$.

\section{TERIMAKASIH}

Penulis mengucapkan terimakasih kepada semua pihak yang membantu keberlangsungan penelitian ini, sehingga peneilitian ini dapat selesai dengan semestinya. Penulis berharap kedepannya banyak inovasi untuk pemanfaatan daun cengkeh agar bernilai guna tinggi.

\section{DAFTAR PUSTAKA}

Asnani, Ari, Eva Vaulina Yulistia Delsy, dan Hartiwi Diastuti., 2019, Transfer Teknologi Produksi Natural Soap-Base Untuk Kreasi Sabun Suvenir, Jurnal Pengabdian Kepada Masyarakat (Indonesian Journal of Community Engagement)., 4(2),129.

BSN., 1994, Standar Mutu Sabun Mandi, SNI, 06-3532-1994.

Hambali E, Bunasor Tatit K, Suryani Ani dan Angga Kusumah GirI., 2005, Aplikasi Dietanolamida Dari Asam Laurat Minyak Inti Sawit Pada Pembuatan Sabun Transparan, Journal of Agroindustrial Technology., 15(2), 46-53.

Haryani, Halima Wahyu, Nur Hidayat, dan Nur Lailatul Rahmah., 2017, Pemurnian Eugenol Dari Minyak Daun Cengkeh Dengan Reaktan Asam Monoprotik, Kajian Jenis Dan Konsentrasi Asam, Jurnal Industrial., 03(2), 83-92.

Kardinan, A, M Iskandar, and Ellyda A Wikardi., 1998, Pengaruh Cara Aplikasi Minyak Suling Melaleuca Bracteata Dan Metil Eugenol Terhadap Daya Pikat Lalat Buah Bactrocera Dorsalis, Jurnal Perlindungan Tanaman Indonesia., 4(1), 38-45. 
Kiswandono, A.A., Nurhasanah, dan Akmal, J., 2020, Workshop Peningkatan Kemampuan Pembuatan Detergen Cair Sebagai Upaya Mengaktifkan Pengurus PKKDesa Fajar Baru, Aptekmas: Jurnal Pengabdian kepada Masyarakat, Politeknik Negeri Sriwijaya.

Mabrouk, Suzanne T., 2005, Making Usable, Quality Opaque or Transparent Soap, Journal of Chemical Education., 82(10), 1534-37.

Ramdan, Yogi Abdul, Sukmawati Utami, dan Endang Endrakasih., 2019, Pengolahan Susu Menjadi Produk Sabun Susu Sapi Indigofera Zollingeriana ( Go-Milk Soap ) Sebagai Upaya Meningkatkan Pendapatan Peternak Sapi Perah Di Daerah Pangalengan Bandung Selatan Processing Fresh Milk Into Indigofera Zollingeriana Milk Soap (Go-Milk Soap) to Increase Dairy Farmers' Income in Pangalengan, Bandung Selatan, Jurnal Agroekoteknologi Dan Agribisnis., Vol 3, No.1.

Sa'diyah, N., N. Hartati, R. A. Raesta, dan L. Kurniasari., 2018, Formulasi Sabun Mandi Padat Berbasis Minyak Biji Kapuk Randu (Ceiba Pentandra Gaertn) Dengan Penambahan Jasmine Oil, Jurnal Inovasi Teknik Kimia., 3(2),8-11.

SNI 3532:2016., 2016, Standar Mutu Sabun Padat, BSN.

Widyasanti, A., S. Junita, dan S. Nurjanah., 2020, Pengaruh Konsentrasi Minyak Kelapa Murni (Virgin Coconut Oil) Dan Minyak Jarak (Castor Oil) Terhadap Sifat Fisikokimia Dan Organoleptik Sabun Mandi Cair, Jurusan Teknologi Hasil Pertanian., 12(02),10-16. 